\title{
PENDUGAAN PARAMETER GENETIK PERFORMA PRASAPIH DOMBA GARUT DI UPTD-BPPTDK MARGAWATI GARUT
}

\author{
HAYA, A.K., ASEP ANANG, DAN DENIE HERIYADI \\ Fakultas Peternakan Universitas Padjadjaran \\ E-mail: ayukamilaa@gmail.com
}

\begin{abstract}
ABSTRAK
Pengembangan sumber daya genetik ternak lokal penting dilakukan untuk memenuhi permintaan daging domba yang tinggi di Indonesia khususnya Jawa Barat melalui kegiatan seleksi bibit unggul Domba garut. Penelitian ini bertujuan untuk mengetahui nilai parameter genetik sifat-sifat prasapih Domba garut. Sifat-sifat yang dianalisis pada penelitian ini yaitu bobot lahir (Bo), bobot 30, 60, 90 hari (B30, B60, B90), dan bobot sapih pada 100 hari (B100) Domba garut di UPTD-BPPTDK Margawati Garut yang berasal dari 104 ekor pejantan, 1.809 ekor induk, 2.921 ekor anak domba jantan, dan 2.632 ekor anak domba betina. Total catatan yang dianalisis yaitu 27.019 catatan bobot badan yang terdiri atas 6.559 catatan Bo, 5.702 catatan B30, 5.248 catatan B6o, 4.843 catatan B9o hari, dan 4.667 catatan B100 Tahun 2012-2019. Analisis data menggunakan Restricted Maximum Likelihood (REML) untuk menduga heritabilitas dengan software Variance Components Estimation (VCE) 6.0, menggunakan model maternal genetic effect $\left(\mathrm{m}^{2}\right)$ dan lingkungan bersama $\left(\mathrm{c}^{2}\right)$. Efek tetap yang dimasukkan ke dalam analisis yaitu jenis kelamin dan tipe kelahiran. Hasil penelitian menunjukkan bahwa nilai heritabilitas Bo, B30, B60, B90, dan B100 menggunakan model maternal genetic effect dan lingkungan bersama yaitu sebesar $0,133 \pm 0,04,0,108 \pm 0,03,0,099 \pm 0,03,0,122 \pm 0,03,0,123 \pm 0,03$, artinya nilai-nilai heritabilitas tersebut masuk dalam kategori rendah. Nilai maternal genetic effect dan lingkungan bersama Bo, B30, B6o, B90, dan B100 Domba garut $0,095 \pm 0,03,0,163 \pm 0,03,0,137 \pm 0,03,0,113 \pm 0,02,0,115 \pm 0,02$ dan $0,455 \pm 0,16,0,268 \pm 0,13,0,274 \pm 0,13$ $0,269 \pm 0,130,278 \pm 0,12$. Hal ini menunjukkan bahwa pendugaan parameter genetik lebih akurat jika melibatkan maternal genetic effect dan lingkungan bersama.
\end{abstract}

Kata kunci: heritabilitas, performa prasapih, maternal genetic effect, lingkungan bersama, domba garut

\section{GENETIC PARAMETERS ESTIMATES OF PREWEANING GARUT SHEEP IN UPTD-BPPTDK MARGAWATI GARUT}

\begin{abstract}
The development of local genetic resources is important to supply the lamb meat which has the high demand in Indonesia especially West Java, through the selection of Garut Sheep superior breeds. This study was addressed to estimate the genetic parameters of Garut Sheep pre-weaning traits. The traits were analyzed on this study were birth weight (Wo), 30, 60, 90 days weight (W30, W60, W90) and weaning weight on 100 days (W100) of Garut Sheep in UPTD-BPPTDK Margawati Garut from 104 sires, 1,809 dams, 2,921 rams, and 2,632 ewes. The total of analyzed records was 27,019 records consists of 6,559 Wo records, 5,702 W30 records, 5,248 W6o records, 4,843 W9o records, and 4,667 W100 records from 2012 - 2019. The data was analyzed Restricted Maximum Likelihood (REML) to estimate the heritability using Variance Components Estimation (VCE) 6.o software, with maternal genetic effect $\left(\mathrm{m}^{2}\right)$ and common environment $\left(\mathrm{c}^{2}\right)$ model. The fixed effects that included in the analysis were sex and birth type. The results showed that the heritability of Wo, W30, W6o, W9o, and W100 using maternal genetic effect and common environment model were $0.133 \pm 0.04,0.108 \pm 0.03,0.099 \pm 0.03,0.122 \pm 0.03,0.123 \pm 0.03$, and it means the heritabilities were in the low category. The maternal genetic effect and common environment values of Garut Sheep Wo, W30, W60, W90, and W100 were $0.095 \pm 0.03,0.163 \pm 0.03,0.137 \pm 0.03,0.113 \pm 0.02$, $0.115 \pm 0.02$ and $0.455 \pm 0.16,0.268 \pm 0.13,0.274 \pm 0.130 .269 \pm 0.130 .278 \pm 0.12$. It showed that the genetic parameters were more accurate if the analysis involved the maternal genetic effect and common environment.
\end{abstract}

Keywords: heritability, pre-weaning performances, maternal genetic effect, common environment, garut sheep 


\section{PENDAHULUAN}

Domba garut merupakan rumpun domba yang dibudidayakan di Indonesia khususnya Jawa Barat. Domba garut juga merupakan sumber daya genetik ternak Jawa Barat yang harus dikembangkan, karena memiliki kemampuan adaptasi yang tinggi terhadap lingkungan, sehingga tidak memerlukan sistem pemeliharaan yang intensif. Domba garut memiliki ciri khas yaitu kombinasi antara kuping rumpung (lebih kecil dari $4 \mathrm{~cm}$ ) atau ngadaun hiris $(4-8 \mathrm{~cm})$ dengan ekor ngabuntut beurit atau ngabuntut bagong (Heriyadi, 2001), dan juga memiliki profil muka cembung, serta bulu pada bagian di seputar lehernya yang dibiarkan tumbuh memanjang (Heriyadi, 2011). Domba garut dijadikan sebagai ternak fancy atau juga dikenal dengan domba tangkas, dan ternak penghasil daging.

Tingkat konsumsi daging domba di Indonesia sebagai salah satu bahan pangan hewani cukup tinggi, khususnya pada provinsi Jawa Barat. Jawa Barat berada di posisi tertinggi dalam mengonsumsi daging domba dari Tahun 2014 - 2018, yaitu 360.929, 370.237, 491.482, 411.723, dan 382.288 ekor (Kementerian Pertanian, 2018). Hal ini menjadi alasan untuk dilakukannya pengembangan sumber daya genetik ternak Jawa Barat yakni Domba garut guna memenuhi permintaan daging domba tersebut.

Pengembangan domba tentunya bergantung pada ketersediaan bibit domba jantan dan betina yang unggul. Cara mendapatkan ketersediaan bibit unggul tersebut tidak terlepas dari kegiatan pemuliaan yaitu seleksi. Seleksi pada domba, penting dilakukan untuk memperoleh kualitas keturunan yang baik, sehingga menghasilkan performa keturunan yang baik. Program seleksi dengan tujuan tersebut, dapat dilakukan pada sifat-sifat kuantitatif domba antara lain, bobot lahir, bobot umur 30, 60, 90 hari, serta bobot sapih. Hal ini karena sifat - sifat tersebut menunjukkan potensi pertumbuhan domba yang akan mempengaruhi produktivitas di masa yang akan datang, dan seleksi dapat dilakukan sedini mungkin, sehingga suatu peternakan terhindar dari kerugian karena memelihara ternak yang kurang produktif.

Seleksi ternak akan menghasilkan keputusan yang akurat apabila berdasarkan pada nilai breeding value atau nilai pemuliaan yang dipengaruhi oleh pendugaan nilai heritabilitas (Boujenane dan Diallo, 2017). Heritabilitas merupakan derajat kemiripan tetua dengan keturunannya dan juga menunjukkan besarnya pengaruh dari gen aditif dari tetua yang diturunkan pada keturunannya. Heritabilitas pada domba biasanya memperhitungkan faktor lain seperti maternal genetic effect $\left(\mathrm{m}^{2}\right)$ dan lingkungan bersama atau common environment $\left(\mathrm{c}^{2}\right)$.
Pengaruh induk terhadap anak terdiri atas sebelum lahir dan setelah lahir. Pengaruh induk sebelum lahir meliputi pengaruh lingkungan uterus induk dan pengaruh genetik induk. Sifat ini merupakan pengaruh induk terhadap anak-anaknya pada masa sebelum lahir, yaitu lingkungan uterus, ukuran plasenta, dan sekresi uterus (Oldenbroek dan Waaij, 2014; Anang et al., 2013). Lingkungan bersama (common environment) merupakan lingkungan yang sama bagi anggota-anggota dari kelompok keluarga yang sama. Pengaruh induk setelah lahir yaitu produksi air susu induk selama menyusui dan kualitas susu induk (Oldenbroek dan Waaij, 2014). Lingkungan bersama perlu diperhitungkan dalam perhitungan parameter genetik, karena dapat menyebabkan dugaan nilai heritabilitas dengan kebiasan yang tinggi (Anang, 2005), sehingga kecermatan seleksi akan menjadi rendah, sebagai konsekuensinya program seleksi yang dilakukan menjadi kurang tepat karena nilai EBV yang dihasilkan pun bias.

Rekording yang lengkap sangat diperlukan dalam pengkajian performa Domba garut untuk memaksimalkan kegiatan seleksi dan evaluasi secara genetik dan pemeliharaan. UPTD-BPPTDK Margawati memiliki sistem rekording yang cukup baik dari Tahun 2012 - 2019, karena sistem rekording balai yang bersangkutan mulai disempurnakan untuk kegiatan seleksi dimulai dari Tahun 2012, sehingga performa dari Domba garut di balai ini berbasis data rekording Tahun 2012 - 2019 dapat dikaji dalam penelitian ini dan dilakukan evaluasi guna perbaikan mutu genetik. Penelitian ini dapat memberikan informasi mengenai Domba garut yang dapat dibudidayakan dan dikembangkan untuk bibit unggul, dan juga dapat dilakukan pengafkiran pada Domba garut yang dianggap mempunyai mutu genetik yang tidak baik.

\section{MATERI DAN METODE}

Penelitian dilakukan dengan metode sensus, teknik pengambilan data secara purposive sampling, dan diolah dengan analisis deskriptif. Jumlah catatan bobot badan pada penelitian ini yaitu sebanyak 27.019 catatan yang terdiri atas 6.559 catatan bobot lahir, 5.702 catatan bobot 30 hari, 5.248 catatan bobot 60 hari, 4.843 catatan bobot 90 hari, dan 4.667 catatan bobot sapih Domba garut Tahun 2012-2019 di UPTDBPPTDK Margawati Garut. Catatan - catatan tersebut berasal dari 104 ekor pejantan, 1.809 ekor induk, 2.921 ekor anak domba jantan, dan 2.632 ekor anak domba betina.

Heritabilitas diduga dengan memperhitungkan maternal genetic effect $\left(\mathrm{m}^{2}\right)$ dan lingkungan bersama $\left(\mathrm{c}^{2}\right)$. Software yang digunakan yaitu Variance and 
Components Estimation, yang merupakan sebuah software untuk menduga nilai heritabilitas serta komponen ragam dengan persamaan matematik sebagai berikut:

$$
\begin{aligned}
& \mathrm{y}=\mathrm{Xb}+\mathrm{Zu}+\mathrm{Wm}+\mathrm{Wc}+\mathrm{e} \\
& \text { Keterangan: } \\
& \mathrm{Y}=\text { Vektor catatan individu (bobot lahir, bobot } 30 \text { hari, bobot } 60 \text { hari, } \\
& \quad \text { bobot } 90 \text { hari dan bobot sapih) berukuran } \mathrm{N} \times 1 \\
& \mathrm{X}=\text { Disain matrik untuk efek tetap } \\
& \mathrm{B}=\text { Vektor untuk efek tetap } \\
& \mathrm{Z}=\text { Disain matrik untuk efek random (seluruh ternak) } \\
& \mathrm{U}=\text { Vektor untuk direct additive genetic effect } \\
& \mathrm{W}=\text { Desain matrik untuk maternal genetic effect dan lingkungan bersama } \\
& \mathrm{m}=\text { Vektor untuk maternal genetic effect } \\
& \mathrm{C}=\text { Vektor untuk lingkungan bersama } \\
& \mathrm{e}=\text { Vektor untuk residu }
\end{aligned}
$$

Nilai Maternal genetic effect dan lingkungan bersama dihitung dengan rumus:

$$
\begin{aligned}
& m^{2}=\frac{\alpha_{m}^{2}}{\alpha_{a}^{2}+\alpha_{m}^{2}+\alpha_{e}^{2}}=\frac{\alpha_{m}^{2}}{\alpha_{p}^{2}} \\
& c^{2}=\frac{\alpha_{c}^{2}}{\alpha_{a}^{2}+\alpha_{c}^{2}+\alpha_{e}^{2}}=\frac{\alpha_{c}^{2}}{\alpha_{p}^{2}}
\end{aligned}
$$

Keterangan:

$\alpha_{\mathrm{a}}{ }^{2}=$ Ragam direct additive genetic effect

$\alpha_{\mathrm{e}}{ }^{2}=$ Ragam lingkungan temporer

$\alpha_{\mathrm{m}}{ }^{2}$ = Ragam maternal genetic effect

$\alpha_{\mathrm{c}}^{2}=$ Ragam lingkungan bersama

$\alpha_{\mathrm{p}}^{2} \quad=$ Ragam fenotip

$\mathrm{A}^{-1} \quad=$ Invers matrik hubungan kekerabatan

I $=$ Matriks identitas

$m^{2} \quad$ = nilai maternal genetic effect

\section{HASIL DAN PEMBAHASAN}

\section{Performa Prasapih}

Rataan bobot lahir pada Tabel 1 menunjukkan hasil sebesar 2,40 kg. Hasil tersebut tidak berbeda jauh dibandingkan menurut SNI 7532:2009, bobot lahir Domba garut jantan dan betina yaitu sebesar 2,8 kg dan 2,4 kg. Namun, hasil rataan bobot lahir tersebut, lebih besar dibandingkan penelitian Anang et al. (2013) pada bangsa domba yang sama dan di balai yang sama berdasarkan data rekording 2012-2013, yaitu sebesar 2,36 kg dan 2,27 kg pada Domba garut jantan dan betina, serta lebih besar dibandingkan hasil penelitian Istiqomah (2006), 2,37 dan 2,39 kg pada Domba garut jantan dan betina. Adanya perbedaan rataan bobot lahir tersebut walaupun pada rumpun domba yang sama, disebabkan oleh banyak faktor yaitu, adanya paritas induk, jenis kelamin, tipe kelahiran, kondisi intra-uterin (lingkungan fetus), genotip induk dan anak, lingkungan induk, nutrisi induk pada masa kebuntingan, Body Condition Score (BCS) induk, lama kebuntingan, dan umur induk (Istiqomah et al., 2006; Ilham, 2015; Thomas et al., 2015).

Tabel 1. Deskripsi data performa prasapih domba garut.

\begin{tabular}{clcc}
\hline No. & Sifat & Rataan $(\mathrm{kg})$ & Koefisien Variasi $(\%)$ \\
\hline 1 & Bobot Lahir & 2,40 & 28,14 \\
2 & Bobot 30 hari & 5,54 & 25,51 \\
3 & Bobot 60 hari & 7,56 & 29,33 \\
4 & Bobot 90 hari & 9,67 & 29,03 \\
\hline
\end{tabular}

Bobot prasapih yang dimaksud dalam penelitian ini adalah bobot domba setelah dilahirkan dan sebelum disapih, yang terdiri atas bobot 30, 60, 90 hari. Rataan bobot 30, 60, 90 hari menurut Tabel 1 yaitu sebesar 5,54 kg, 7,56 kg, dan 9,67 kg. Hasil ini lebih rendah dibandingkan penelitian Anang et al. (2013), bobot domba pada umur 30, 60, 90 hari pada Domba garut jantan dan betina yaitu sebesar 6,44 kg, 8,46 kg, 10,29 $\mathrm{kg}$, dan $6,15 \mathrm{~kg}, 8 \mathrm{~kg}, 9,58 \mathrm{~kg}$. Perbedaan tersebut disebabkan catatan rekording yang digunakan untuk penelitian berbeda. Faktor lain yang mempengaruhi bobot prasapih yaitu bobot lahir. Bobot lahir mempengaruhi laju pertumbuhan prasapih, sehingga laju pertumbuhan domba dengan bobot lahir rendah terlihat lebih lambat dibandingkan anak domba yang bobot lahirnya tinggi (Sumadi et al., 2014; Boujenane dan Diallo, 2017). Namun, selain itu faktor nongenetik lainnya juga berpengaruh pada bobot prasapih, misalnya jenis kelamin, tipe kelahiran, paritas, dan faktor tatalaksana pemeliharaan.

Rataan bobot sapih hasil penelitian ini sebesar 10,67 $\mathrm{kg}$. Hasil tersebut tidak berbeda jauh dibandingkan SNI 7532:2009, bobot sapih Domba garut jantan dan betina yaitu sebesar 11,5 kg dan 9,1 kg. Namun, hasil rataan bobot lahir hampir sama jika dibandingkan penelitian Anang et al. (2013), yaitu sebesar 11,5 kg dan $10,64 \mathrm{~kg}$ pada Domba garut jantan dan betina, serta Sumadi (2017), yaitu sebesar 14,63 dan 10,60 kg pada Domba garut jantan dan betina. Adanya perbedaan rataan bobot lahir tersebut walaupun pada rumpun domba yang sama, disebabkan oleh banyak faktor yaitu, kondisi pakan, paritas induk, BCS induk, nutrisi induk pada masa kebuntingan, jenis kelamin, tipe kelahiran (Ilham, 2015; Thomas et al., 2015). Bobot sapih juga dipengaruhi oleh bobot lahir yang dihasilkan karena menurut Istiqomah (2006), bobot lahir memiliki korelasi yang positif dengan bobot sapih, artinya kemajuan seleksi pada bobot lahir akan mengakibatkan meningkatnya kemajuan genetik untuk bobot sapih.

Koefisien Variasi (KV) bobot badan prasapih Domba garut berkisar antara 25,51\% sampai dengan 29,33\%. Hal ini menunjukkan bahwa bobot badan yang ada pada UPTD-BPPTDK Margawati Garut, memiliki keragaman yang tinggi. Menurut Nasution (1992), suatu data dapat 
dikatakan seragam jika memiliki nilai KV yang berada di bawah $15 \%$. Hal tersebut menunjukkan bahwa bobot badan yang diamati sangat beragam karena memiliki nilai KV yang lebih besar dari $15 \%$, sehingga semakin tinggi tingkat keragaman pada populasi, akan semakin efektif seleksi yang dilakukan.

\section{Parameter Genetik \\ Pendugaan Komponen Ragam}

Dugaan komponen ragam dari masing-masing sifat yang dianalisis dengan model tersebut disajikan pada Tabel 2. Berdasarkan Tabel 2, ragam aditif dan lingkungan bobot lahir, bobot 30, 60, 90 hari, dan bobot sapih berkisar antara 0,0651 - 1,2272 dan 0,1557 - 4,8163. Pengaruh lingkungan dalam mempengaruhi performa prasapih domba lebih beragam dibandingkan pengaruh genetik aditif, karena besar ragam lingkungan yang lebih besar dibandingkan ragam genetik aditif. Selain pengaruh gen aditif, faktor genetik yang juga terdiri atas pengaruh genetik induk dan gen dominan serta pengaruh lingkungan yang terdiri atas lingkungan bersama dan lingkungan secara umum. Hal ini disebabkan lingkungan bersama dapat meningkatkan kemiripan antar anak yang dipelihara di lingkungan yang sama. (Anang, 2005; Oldenbroek dan Waaij, 2014), sehingga jika komponen ragam dianalisis yang tidak memperhitungkan maternal genetic effect dan lingkungan bersama, hasilnya akan bias.

Tabel 2. Dugaan komponen ragam performa prasapih domba garut

\begin{tabular}{cccccc}
\hline No. & Sifat & $\sigma^{2} \mathrm{a}$ & $\sigma^{2} \mathrm{e}$ & $\sigma^{2} \mathrm{~m}$ & $\sigma^{2} \mathrm{c}$ \\
\hline 1 & Bobot Lahir & 0,0651 & 0,1557 & 0,0464 & 0,2234 \\
2 & Bobot 30 hari & 0,2211 & 0,9397 & 0,3332 & 0,5478 \\
3 & Bobot 60 hari & 0,5046 & 2,4852 & 0,6979 & 1,3952 \\
4 & Bobot 90 hari & 1,0285 & 4,1462 & 0,9504 & 2,2597 \\
5 & Bobot Sapih & 1,2271 & 4,8163 & 1,1439 & 2,7635 \\
\hline
\end{tabular}

Keterangan:

$\sigma^{2} a:$ Ragam genetik aditif

$\sigma^{2} \mathrm{e}$ : Ragam lingkungan

$\sigma^{2} \mathrm{~m}:$ Ragam genetik induk

$\sigma^{2} c$ : Ragam lingkungan

Kisaran ragam genetik induk dan lingkungan bersama hasil analisis yaitu antara 0,0464 - 1,1439 dan $0,2234-2,7635$. Pengaruh lingkungan bersama terhadap bobot prasapih domba cenderung lebih beragam dibandingkan pengaruh genetik aditif dan maternal genetic effect, hal ini menyebabkan induk domba garut di Balai Margawati mempunyai peran yang sangat besar dalam membesarkan anaknya. Kemampuan induk dalam membesarkan anaknya menyebabkan kemiripan anak antar famili, kerena adanya pengaruh kebersamaan, pengaruh lingkungan induk, dan maternal genetic effect.

\section{Pendugaan Nilai Heritabilitas}

Menurut Kurnianto (2009), nilai heritabilitas berkisar antara o sampai 1, dan heritabilitas juga dikelompokkan ke dalam tiga kategori, yaitu rendah (o $-0,15)$, sedang $(0,15-0,30)$ dan tinggi $(\geq 0,30)$. Nilai heritabilitas dari masing-masing sifat pada berada pada kisaran 0,099-0,133, sehingga nilai heritabilitas bobot lahir, bobot 30, 60, 90 hari, dan bobot sapih masuk pada kategori rendah (Tabel 3). Menurut Boujenane dan Diallo (2017), Zishiri et al. (2014), Dudi (2007), dan Anang et al. (2013), adanya pemisahan pengaruh genetik aditif dengan maternal genetic effect dan lingkungan bersama pada analisis parameter genetik menghasilkan nilai heritabilitas yang rendah.

\begin{tabular}{clccc}
\multicolumn{4}{c}{ Tabel 3. Dugaan parameter genetik performa prasapih domba garut } \\
\hline No. & Sifat & $\mathrm{h}^{2} \pm \mathrm{se}$ & $\mathrm{m}^{2} \pm \mathrm{se}$ & $\mathrm{c}^{2} \pm \mathrm{se}$ \\
\hline 1 & Bobot Lahir & $0,133 \pm 0,04$ & $0,095 \pm 0,03$ & $0,455 \pm 0,16$ \\
2 & Bobot 30 hari & $0,108 \pm 0,03$ & $0,163 \pm 0,03$ & $0,268 \pm 0,13$ \\
3 & Bobot 60 hari & $0,099 \pm 0,03$ & $0,137 \pm 0,02$ & $0,274 \pm 0,13$ \\
4 & Bobot 90 hari & $0,122 \pm 0,03$ & $0,113 \pm 0,02$ & $0,269 \pm 0,13$ \\
5 Bobot Sapih & $0,123 \pm 0,03$ & $0,115 \pm 0,02$ & $0,278 \pm 0,12$
\end{tabular}

Keterangan:

h2 : Heritabilitas

m2 : Maternal genetic effect

Pengaruh lingkungan bersama

Standard error

Menurut hasil penelitian Anang et al. (2013) pada Domba garut di balai yang sama, nilai heritabilitas bobot lahir, bobot 30, 60, 90 hari, dan bobot sapih domba garut yaitu sebesar $0,089 \pm 0,07,0,191 \pm 0,13$, 0,262 \pm 0,10, 0,206 \pm 0,11, dan 0,233 $\pm 0,09$, dengan menyertakan model maternal genetic effect dan lingkungan bersama. Jika dibandingkan dengan hasil analisis pada Tabel 3, nilai heritabilitas hanya meningkat pada bobot lahir saja, sedangkan pada bobot 30, 60, 90 hari, dan bobot sapih menurun. Namun menurut hasil penelitian Sumadi et al. (2017), nilai heritabilitas bobot sapih ddi balai yang sama yaitu sebesar $0,45 \pm 0,08$ artinya nilai heritabilitas termasuk kategori tinggi. Hal ini disebabkan karena pada penelitian tersebut tidak disertakan maternal genetic effect dan lingkungan bersama. Walaupun penelitian-penelitian tersebut dilakukan pada sifat yang sama, bangsa domba yang sama, dan di tempat yang sama dengan waktu yang berbeda, pastinya ada perbedaan data yang digunakan pada penelitian, sehingga adanya perbedaan generasi, sehingga nilai heritabilitas yang dihasilkan pun akan berbeda pula (Faid et al., 2016). Adanya perbedaan metode yang digunakan dalam penelitian juga dapat menghasilkan hasil yang berbeda.

Nilai heritabilitas bobot lahir pada Tabel 3, lebih besar dibandingkan hasil penelitian Dudi (2007) pada domba priangan sebesar 0,02, Boujenane et al. (2015) 
pada domba D'man sebesar 0,05, Haile et al. (2018) pada Domba Awassi sebesar 0,03, Boujenane dan Diallo (2017) pada domba sardi sebesar 0,09, Kiya et al. (2019) pada domba dorper sebesar 0,11, dan serupa dengan hasil penelitian Zishiri et al. (2014) pada domba Ile de France sebesar 0,13. Namun, nilai heritabilitas bobot lahir domba garut pada penelitian ini lebih kecil dibandingkan hasil penelitian Zishiri et al. (2014) pada domba dormer sebesar 0,25 dan Faid et al. (2016) pada domba romney sebesar 0,20.

Nilai heritabilitas bobot 30 hari pada Tabel 3, lebih besar dibandingkan hasil penelitian Boujenane dan Diallo (2017) pada domba sardi sebesar o,06 dan Boujenane et al. (2015) pada domba D'man sebesar o,03, namun lebih kecil dibandingkan hasil penelitian Kiya et al. (2019) pada domba dorper sebesar 0,12, namun nilai heritabilitas bobot 60 hari jauh lebih kecil dibandingkan hasil penelitian Kiya et al. (2019) Sebesar o,14. Nilai heritabilitas bobot 90 hari pada Tabel 3 lebih besar dibandingkan hasil penelitian Boujenane et al. (2015) pada domba D'man sebesar 0,08 dan Boujenane dan Diallo (2017) pada domba sardi sebesar 0,05.

Nilai heritabilitas bobot sapih pada Tabel 3, lebih besar dibandingkan hasil penelitian Dudi (2007) pada domba priangan sebesar 0,08 , Haile et al. (2018) pada domba awassi sebesar 0,06, namun lebih kecil dibandingkan hasil penelitian Zishiri et al. (2014) pada domba dormer dan Ile de France sebesar 0,28 dan 0,14, Faid et al. (2016) pada domba romney sebesar 0,15, dan Kiya et al. (2019) pada domba dorper sebesar 0,21. Nilai heritabilitas hasil penelitian dengan memperhitungkan maternal genetic effect dan lingkungan bersama termasuk dalam kategori rendah karena nilai-nilai heritabilitas tersebut sebesar $0-0,15$, dan sebagian kecil termasuk dalam kategori sedang $(0,15-0,30)$. Hal tersebut menunjukkan bahwa dalam melakukan program seleksi disarankan untuk melibatkan maternal genetic effect dan lingkungan bersama untuk meminimalisir adanya bias pada program seleksi.

Nilai maternal genetic effect dan lingkungan bersama yang dihasilkan berkisar antara 0,095 o,163 dan 0,268 - 0,455, sedangkan nilai maternal genetic effect $\left(\mathrm{m}^{2}\right)$ dan lingkungan bersama pada bobot lahir, bobot 30, 60, 90 hari, dan bobot sapih menurut penelitian Anang et al. (2013), yaitu berada pada kisaran 0,193 - 0,299 dan 0,447 - 0,562. Jika dibandingkan, nilai maternal genetic effect dan pengaruh lingkungan bersama cenderung lebih rendah, yang berarti kedua faktor tersebut memiliki kemampuan menurunkan nilai heritabilitas yang hanya didasarkan direct additive genetic effect lebih rendah dibandingkan hasil penelitian sebelumnya, namun nilai lingkungan bersama keduanya lebih besar dibandingkan maternal genetic effect.
Nilai maternal genetic effect hasil penelitian ini tidak berbeda jauh dibandingkan hasil penelitian Dudi (2007) pada domba priangan dengan kisaran 0,12 0,15 , walaupun perbandingan nilai maternal genetic effect pada bobot lahir terlampau jauh. Nilai maternal genetic effect cenderung lebih besar dibandingkan hasil penelitian Zishiri et al. (2014) pada domba dormer dan Ile de France dengan kisaran 0,05-0,07 dan 0,02-0,10, Boujenane dan Diallo (2017) pada domba sardi dengan kisaran 0,01 - 0,07, Haile et al. (2018) pada domba awassi dengan kisaran 0,02 - 0,03, dan Boujenane et al. (2015) pada domba D'man dengan kisaran 0,07 - 0,10, namun lebih kecil jika dibandingkan dengan hasil penelitian Faid et al. (2016) pada domba romney dengan kisaran 0,41 - 0,59 dan Kiya et al. (2019) dengan kisaran o,16 - 0,22. Perbedaan hasil tersebut tentunya disebabkan karena perbedaan bangsa domba yang menjadi objek penelitian.

Nilai lingkungan bersama lebih besar dibandingkan hasil penelitian Zishiri et al. (2014) pada domba dormer dan Ile de France dengan kisaran 0,08 - 0,11 dan 0,09 - 0,18, dan Boujenane dan Diallo (2017) pada domba sardi dengan kisaran 0,04-0,10, namun lebih kecil jika dibandingkan hasil penelitian Dudi (2007) pada domba priangan dengan kisaran o,68 0,77 . Nilai lingkungan bersama pada penelitian ini dan hasil penelitian Dudi (2007) sama - sama lebih besar kisarannya dibandingkan nilai maternal genetic effect. Hal ini menunjukkan bahwa induk domba garut di Balai Margawati mempunyai peran yang sangat besar dalam membesarkan anaknya, dan kemiripan antar anak domba yang dipeliharan dalam lingkungan yang sama memiliki pengaruh yang besar dalam mempengaruhi performa domba. Menurut Oldenbroek dan Waaij, (2014), pengaruh lingkungan bersama juga penting untuk diperhitungkan pada analisis komponen ragam dan parameter genetik, karena lingkungan bersama dapat meningkatkan kemiripan antar anak pada lingkungan yang sama.

\section{SIMPULAN}

Berdasarkan hasil penelitian pada domba garut di UPTD-BPPTDK Margawati Garut Tahun 2012-2019, efek tetap sebagai faktor non-genetik pada domba yaitu jenis kelamin dan tipe kelahiran mempengaruhi keragaman performa prasapih. Heritabilitas yang dihasilkan pada masing-masing sifat prasapih domba garut dengan menggunakan maternal genetic effect dan lingkungan bersama termasuk dalam kategori rendah, sehingga dengan memperhitungkan kedua faktor tersebut kegiatan seleksi yang dilakukan dapat diminimalisasi tingkat kebiasaannya dan lebih akurat. 


\section{UCAPAN TERIMAKASIH}

Penulis berterimakasih kepada Kepala Dinas Ketahanan Pangan dan Peternakan Jawa Barat serta Kepala dan Staf UPTD-BPPTDK Margawati yang telah mengizinkan penulis untuk melakukan penelitian di balai Margawati, dan kepada semua pihak yang telah membantu penelitian dan analisis, sehingga artikel ini dapat diselesaikan.

\section{DAFTAR PUSTAKA}

Anang A., H. Indrijani, D. Rahmat, dan Dudi. 2013. Uji Performance Domba Garut di UPTD BPPTD Margawati Garut Jawa Barat. Laporan Penelitian. Balai Pengembangan Perbibitan Ternak Domba Jawa Barat. Fakultas Peternakan Univeristas Padjadjaran, Bandung.

Badan Standardisasi Nasional. 2009. Standar Nasional Indonesia Bibit Domba garut (SNI: 7532:2009). Jakarta.

Boujenane, I. dan I.T. Diallo. 2017. Estimates of genetic parameters and genetic trends for pre-weaning growth traits in Sardi sheep. Small Ruminant Research. 146: 61-68.

Boujenane, I., A. Chikhi, M. Ibnelbachyr, dan F.Z. Mouh. 2015. Estimation of genetic parameters and maternal effects for body weight at different ages in D'man sheep. Small Ruminant Research. 13: 27-35.

Dudi. 2007. Pendugaan nilai pemuliaan dan tren genetik bobot badan prasapih domba priangan menggunakan animal model BLUP. Jurnal Ilmu Ternak. 7 (2): 107-112.

Faid-Allah E., E. Ghoneim, dan A.H.M. Ibrahim. 2016. Estimated variance components and breeding values for pre-weaning growth criteria in Romney sheep. JITV. 21(2): 73-82.

Hardjoesoebroto, W. 1994. Aplikasi Pemuliabiakan Ternak di Lapangan. Gramedia Widiasarana Indonesia, Jakarta. Hal. 6-7, 28-30, 210-213.

Heriyadi, D. 2011. Pernak Pernik Senarai Domba Garut. Unpad Press. Bandung. Hal. 1-8, 188.

Heriyadi, D., A. Sarwestri, dan D.C Budinuryanto. 2001. Ngawangkong Peternak Domba Tangkas. Laporan Penelitian. Kerjasama antara Fakultas Peternakan, IKA Fakultas Peternakan, dan Pusat Dinamika Pembangunan Universitas Padjadjaran. Bandung.

Ilham, F. 2015. Bobot Lahir, Bobot 90 hari, dan Bobot 180 Hari Domba Lokal yang Dipelihara di Padang Penggembalaan. Jurnal Ilmiah Agrosains Tropis.

Istiqomah L., C. Sumantri dan T.R. Wiradarya. 2006. Performa dan evaluasi genetik bobot lahir dan bobot sapih Domba Garut di peternakan ternak domba sehat Bogor. J. Indon. Trop. Anim. Agric. 31(4): 232-242.

Kementrian Pertanian. 2018. Statistik Peternakan dan Kesehatan Hewan. Direktorat Jenderal Peternakan dan Kesehatan Hewan.

Kiya C.K., V.B. Pedrosa., K.F.A. Muniz., A.L. Gusmao, dan L.F.B. Pinto. 2019. Estimates of genetic parameters of a dorper flock in Brazil. Small Ruminant Research 171, Elsevier. 57-62.

Kurnianto, E. 2009. Pemuliaan Ternak. Graha Ilmu. Yogyakarta. Hal. 31-32, 64-65, 107.

Mukhtiani A., J. Achmadi, B.I.M. Tampoebolon, dan R. Setyorini. 2013. Pemberian silase limbah sayuran yang disuplementasi dengan mineral dan alginat sebagai pakan domba. JITP 2(3): 144-151.

Nasution, A. H. 1992. Pamduan Berpikir dan Meneliti Secara Ilmiah bagi Remaja. Gramedia. Jakarta.

Oldenbroek K. dan L.V.D Waaij. 2014. Animal breeding and Genetics. Centre for Genetic Resources and Animal Breeding and Genomics Group, Wageningen University and Research Centre. Netherlands. Hal. 162, 176.

Rahmat D., A. Anang, dan Dudi. 2007. Kecermatan Dugaan Respon Seleksi Bobot Badan Prasapih Domba Priangan Berdasarkan Catatan Tunggal dan Catatan Berulang. Seminar Nasional PeternakanPerikanan 2007.

Sumadi, T. Hartatik, D. Maharani, A. Fathoni, A. Nurrudin, dan D. N. H. Hariyono. 2017. The Estimation of Breeding Value of Rams at Technical Implementation Unit Development Center for Livestock Breeding in Margawati Garut, West Java. Proceeding of The $1^{\text {st }}$ International Conference on Tropical Agriculture. Department of Animal Breeding and Reproduction, Faculty of Animal Science, UGM, Yogyakarta.

Sumadi, T. Hartatik, D. Maharani, A. Fathoni, A. Nurrudin, dan D.N.H. Hariyono. 2017. The Estimation of Breeding Value of Rams at Technical Implementation Unit Development Center for Livestock Breeding in Margawati Garut, West Java. Proceeding of The $1^{\text {st }}$ International Conference on Tropical Agriculture. 445-452.

Thomas, R.A.C., R.E Hickson, S.T. Morris, P.J. Back, A.L. Ridler, K.J. Stafford, dan P.R. Kenyon. 2015. Effects of Body Condition Score and Nutrition in Lactation on Twin-Bearing Ewe and Lamb Perfomance to Weaning. New Zealand of Agricultural Research 58(2): 156-169.

Zishiri O.T., S.W.P. Cloete., J.J. Olivier., dan K. Dzama. 2014. Genetic Parameters for Live Weight Traits in South African Terminal Sire Sheep Breeds. Small Ruminant Research 116, Elsevier. 118-125. 